\title{
EDITORIAL
}

\section{Do we need to innovate in critical care practice?}

\author{
Lluis Blanch ${ }^{* 1}$, Ramon Maspons ${ }^{2}$ and Gloria Palomar ${ }^{3}$
}

Clinical work and continuous investigation have improved the outcome of critically ill patients over time. Nowadays, innovation pulled by demand and translational research projects of excellence will constitute new opportunities for clinicians to improve care and provide economic incentives to be returned to the patient, institutions, and society.

Over 60 years of clinical work and research in critical care medicine have improved survival in critically ill patients. This improvement is due to better treatment of disease in target organs and better treatment of problems such as sepsis, and also due to interdisciplinary approaches, early detection, and integrative information systems $[1,2]$. Intensivists work with cutting-edge technologies limited by financial constraints, so the cost/ efficiency of each ICU process is analyzed in detail [3]. However, epidemiologic research, physiologic research, and translational research have yielded mixed results. Despite notable advances, expensive large randomized clinical trials have yielded disappointing results in many areas. We must therefore reorient translation research and also exploit our knowledge to promote innovation studies that enable faster application in clinical practice. Innovation studies can lead to benefits for professionals, institutions, and society [4].

Opportunities for innovation in critical care abound. Critical care is personalized, and the patient is the key element. Since professionals and patients have pivotal roles, innovation will be pulled by demand. Interdisciplinary work with other medical or nonmedical disciplines can drive innovation. Programs to improve ventilated patients' mobility would be impossible without the close collaboration of physical therapists, nurses, and related industry [5]. Likewise, designing and applying neurocognitive rehabilitation programs to prevent longterm sequelae require collaboration with informatics engineers and neuropsychologists [6,7]. Huge amounts of

\footnotetext{
*Correspondence: Iblanch@tauli.cat

${ }^{1}$ Critical Care Department, Parc Taulí Sabadell, Hospital Universitari, Corporació

Sanitària Parc Taulí, Sabadell, Universitat Autònoma de Barcelona, CIBER

Enfermedades Respiratorias, Instituto de Salud Carlos III, Madrid, Spain

Full list of author information is available at the end of the article
}

data are stored in electronic records for each patient, and exploiting these data could lead to benefits. Integrative information systems can improve decision-making, as is evidenced by patient response to therapy based on the use of different monitoring devices [8-10]. Critical care is among the first places in the hospital to incorporate new technologies, providing opportunities to collaborate with the health industry in developing new products designed through common knowledge and to share final outputs and benefits. Knowledge resides in the clinical arena, so intensivists and their teams must be more than final users.

Instead of viewing critical care as a drain through which large proportions of limited resources disappear, we must consider these departments as opportunities for long-term economic growth. Innovation in public institutions must provide economic incentives to be returned to the patient, institutions, and society in terms of much better care. Intensivists face a new era in which old paradigms must be replaced with new business models; this path is full of uncertainties, but is very exciting $[1,2]$.

\section{Competing interests \\ $L B$ is investigator of the project'Early Neurocognitive Rehabilitation in Critically III Patients with Acute Acquired Brain Injury'funded by La Fundació Marató TV3 2010. LB and GP have developed patented inventions related to monitoring ventilator signals. The license for these patents belongs to Corporació Sanitària Parc Taulí (Spain). LB and GP own 10\% respectively of BetterCare S.L., a research and development spin-off of Corporació Sanitària Parc Taulí (Spain). RM declares that he has no competing interests.}

\section{Author details}

'Critical Care Department, Parc Taulí Sabadell, Hospital Universitari, Corporació Sanitària Parc Taulí, Sabadell, Universitat Autònoma de Barcelona, Parc Tauli, 1, 08208 Sabadell, Spain, CIBER Enfermedades Respiratorias, Instituto de Salud Carlos III, Sinesio Delgado, 4, 28029 Madrid, Spain. Innovation Office (CINO), Agencia de Qualitat i Avaluació Sanitàries de Catalunya, Roc Boronat, 81-95, Barcelona, Spain. ${ }^{3}$ Fundació Parc Taulí, Universitat Autònoma de Barcelona, Parc Taulí, 1, 08208 Sabadell, Spain

\section{Published: 4 July 2013}

\section{References}

1. Vincent JL, Singer M, Marini JJ, Moreno R, Levy M, Matthay MA, Pinsky M, Rhodes A, Ferguson ND, Evans T, Annane D, Hall JB: Thirty years of critical care medicine. Crit Care 2010, 14:311.

2. Blanch L, Annane D, Antonelli M, Chiche JD, Cuñat J, Girard TD, Jiménez EJ, Quintel M, Ugarte S, Mancebo J: The future of intensive care medicine. Med Intensiva 2013, 37:91-98.

3. Needham DM: Patient safety, quality of care, and knowledge translation in the intensive care unit. Respir Care 2010, 55:922-928.

4. Blanch L, Palomar G: Innovation in intensive care medicine: yes, we must. Med Intensiva 2013, 37:3-5. 
5. Lord RK, Mayhew CR, Korupolu R, Mantheiy EC, Friedman MA, Palmer JB, Needham D: ICU early physical rehabilitation programs: financial modeling of cost savings. Crit Care Med 2013, 41:717-724.

6. Herridge MS, Tansey CM, Matté A, Tomlinson G, Diaz-Granados N, Cooper A, Guest CB, Mazer CD, Mehta S, Stewart TE, Kudlow P, Cook D, Slutsky AS, Cheung AM; Canadian Critical Care Trials Group: Functional disability 5 years after acute respiratory distress syndrome. N Eng/ J Med 2011, 364:1293-1304.

7. Turon M, Fernandez-Gonzalo S, Gomez-Simon V, Blanch L, Jodar M: Cognitive stimulation in ICU patients: should we pay more attention? Crit Care 2013, 17:158.

8. Cooke CR, Iwashyna TJ: Using existing data to address important clinical questions in critical care. Crit Care Med 2013, 41:886-896.

9. Brochard L, Martin GS, Blanch L, Pelosi P, Belda FJ, Jubran A, Gattinoni L,
Mancebo J, Ranieri VM, Richard JC, Gommers D, Vieillard-Baron A, Pesenti A, Jaber S, Stenqvist O, Vincent JL: Clinical review: Respiratory monitoring in the ICU - a consensus of 16. Crit Care 2012, 16:219.

10. Blanch L, Sales B, Montanya J, Lucangelo U, Garcia-Esquirol O, Villagra A, Chacon E, Estruga A, Borelli M, Burgueño MJ, Oliva JC, Fernandez R, Villar J, Kacmarek R, Murias G: Validation of the Better Care system to detect ineffective efforts during expiration in mechanically ventilated patients: a pilot study. Intensive Care Med 2012, 38:772-780.

doi:10.1186/cc12769

Cite this article as: Blanch $L$, et al:: Do we need to innovate in critical care practice? Critical Care 2013, 17:166. 